\title{
EdiçÃo Temática Conhecimento, Escola e Cultura(s) - Apresentação
}

\author{
BORGES, Luis Paulo Cruz ${ }^{1}$ \\ CASTRO, Paula Almeida de ${ }^{2}$
}

Esta edição da e-Mosaicos, que tem como tema "Conhecimento, Escola e Cultura(s)", está delineada na perspectiva da produção do conhecimento e das culturas, considerando estes eixos analíticos para uma reflexão crítica sobre a educação pública na contemporaneidade.

A composição da edição temática, parte da cultura como referencial socioantropológico para buscar o entendimento sobre as interações entre os sujeitos escolares e ancora-se no conhecimento como base teórico-epistemológica e político-social para refletir sobre os rumos da escola inserida em uma sociedade em constante transformação.

Neste contexto, evidencia-se a formação identitária dos sujeitos escolares que em seus processos formativos modificam a condição de vida dentro e fora dos meios educacionais e as aproximações e distanciamentos entre os indivíduos movimentam traços de suas culturas de origem, que se juntam através de interações sociais e legitimam os espaços pelas diferenças.

$\mathrm{Na}$ esteira desse delineamento é que foi composta esta edição temática com os artigos que indicam, em seus estudos, as discussões sobre as políticas públicas para a formação de professores, seus currículos e contextos culturais permeados pela violência social e escolar, gênero, letramento, tecnologias educacionais e os processos de inclusão como transposição das fronteiras entre os sujeitos e a cultura escolar.

A seção Opinião aborda a discussão sobre a estrutura das escolas públicas no Paquistão "Pakistani Schools: a Cultural Structure Analysis" apresentando a necessidade de considerar alguns fatos importantes para lidar com o processo de formação nas escolas do país, gênero e radicalização através de um programa de Reformas Educacionais no Paquistão como um pacote único. $O$ argumento do autor indica a necessidade de analisar o que está fora da caixa, que trata de resultados de pesquisa e que possam pautar as soluções próprias para o país. Uma das questões mais importantes a serem analisadas é o fato de que no Paquistão há escolas densamente povoadas e infraestrutura deficiente disponível, o que inviabiliza alocar mais 25 milhões de alunos. Por outro lado, não se pode deixá-los esperar até que as escolas sejam construídas e os professores sejam empregados e preparados, de modo que a qualidade da educação, a pobreza, a falta de interesse dos pais e a formação de professores sejam postos em um estado de comprometimento.

Quanto à necessidade de revisitar o estado de comprometimento, pode-se propor uma análise da formação de professores e um viés para a melhoria da qualidade desse processo através do Programa de Bolsa de Iniciação à Docência (PIBID) da CAPES. Dados

\footnotetext{
${ }^{1}$ Professor do Instituto de Aplicação Fernando Rodrigues da Silveira da Universidade do Estado do Rio de Janeiro. Email: borgesluispaulo@yahoo.com.br

${ }^{2}$ Professora do Centro de Educação da Universidade Estadual da Paraíba. Email: paulaalcastro@terra.com.br
} 


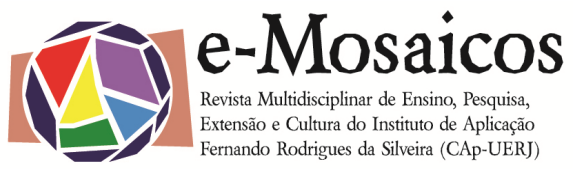

apresentados a partir de uma pesquisa, o artigo "Escola e formação de professores: problematização e investigação sobre o trabalho docente no PIBID" investigou os diferenciais da parceria universidade-escola básica para a formação inicial de pedagogos docentes no contexto do PIBID. Entendemos que o PIBID potencializa a aprendizagem da docência dos licenciandos bolsistas integrando à prática do professor supervisor da escola parceira. Essa aprendizagem se expressa no desenvolvimento de uma postura investigativa colocando a escola como espaço-tempo central à formação docente.

Observa-se um crescente movimento em torno da integração entre a universidade e a escola de educação básica como proposta para a melhoria dos processos formativos e de ensino e aprendizagem. Tanto em programas de bolsa como o PIBID, quanto através da realização de pesquisas que identificam nos alunos um caminho para a compreensão da escola e seus sujeitos ao mesmo tempo em que protagonizam a formação docente através do contato com a cultura escolar. Nessa perspectiva apresenta-se o artigo "Coparticipação de alunos e alunas na pesquisa: compartilhar e criar significados sobre a escola", iniciado com uma discussão teórico-metodológica sobre a coparticipação de alunos, alunas da educação básica de escolas públicas em pesquisas educacionais. As bases que orientaram a pesquisa foram: os fundamentos da etnografia expressos nos estudos sobre colaboração e reflexividade; as diferentes formas de coparticipação de alunos como agentes do conhecimento escolar pautadas nos estudos sobre "a voz do aluno" [Student Voice]; e, os princípios da pesquisa-crítico-participativa a partir de uma concepção mais democrática e simétrica de poder entre os membros da equipe. Os principais resultados da pesquisa indicam a experiência positiva para os grupos envolvidos, indicando essa abordagem pode modificar as formas de desenvolver pesquisas nas escolas.

Sobre as possibilidades de integrar professores em formação com práticas diferenciadas é que se propõe a realização de viagens com alunos para identificar elementos culturais tornando-se um potente recurso de conhecimento e formação docente. No artigo "Expedição pedagógica e coletivos docentes na América latina: outros modos de formação", busca-se rememorar uma experiência vivida no e com o Núcleo de Pesquisa e Extensão Vozes da Educação - História e Memória das Escolas de São Gonçalo denominada Expedição Pedagógica. Esta atividade aconteceu na cidade de Neuquén, Argentina, entre os dias 23 e 27 de maio de 2012, com docentes da Venezuela, de Argentina e Brasil. O artigo trata de discutir o conceito de Expedição Pedagógica ao mesmo tempo em que discute os atravessamentos experimentados pela autora durante essa atividade. Apoiada, especialmente, no trabalho do filósofo Walter Benjamin, a autora reflete sobre a importância de não deixar as experiências caírem no esquecimento, algo frequente na modernidade.

Com a mesma proposta de integrar os saberes dos diferentes espaços educacionais o artigo "Discussões iniciais sobre lesbianidades e educação escolar" propõe discussão da temática sexualidade com ênfase na diversidade sexual no campo da educação. Ainda que tenha sido observado o aumento da produção acadêmica brasileira em torno dessa área, parte muitíssimo pequena de tais pesquisas tem como eixo central as experiências de mulheres lésbicas. O texto se localiza deste modo, numa tentativa de abordar este tema pouco visibilizado, por meio da apresentação das reflexões iniciais da pesquisa, na qual os autores propõem trabalhar com as experiências escolares de lésbicas egressas da escola pública. Por meio do levantamento bibliográfico, ora apresentado, evocam-se os estudos sobre lesbianidades, a questão da visibilidade e, por fim, a lesbofobia nas instituições de ensino.

O fazer docente permeado por um sem números de caminhos é constantemente desafiado a incorporar novas possibilidades para formar alunos e futuros profissionais. A inserção das tecnologias digitais nesse fazer é destacado no artigo "Perseu e Medusa: os 
enfrentamentos das práticas escolares de letramento digital do professor", analisado na perspectiva da pesquisa etnográfica aborda a discussão sobre a prática docente e seus usos no cotidiano da sala de aula. A analogia feita a Perseu e Medusa nos remete aos enfrentamentos diários do professor para estabelecer, com as tecnologias, elaborações mais orientadas com as demandas não apenas dos alunos, mas as próprias. A pesquisa realizada com sujeitos - alunos e professores - de uma escola pública de Educação Básica do município de São Bento do Una (PE) que disponibiliza recursos digitais (lousas, equipamentos de informática, dentre outros em perfeito) para o uso em sala de aula. 0 estudo buscou analisar e apresentar a perspectiva do professor - sujeito da pesquisa sobre os usos das tecnologias disponibilizadas pelas escolas e a apropriação dos mesmos para a elaboração das aulas. Verificou-se o impacto das mídias nos processos de ensino e aprendizagem e a necessidade de uma provocação para que os docentes desfaçam os mitos e busquem nas tecnologias os caminhos para a melhoria da qualidade do ensino.

As tecnologias e seus usos na escola e na sala de aula apresentam-se como possibilidades de modificar o cenário educacional visando melhorias, numa linha paralela à proposta do PIBID e das políticas públicas de educação inclusiva, integrando os saberes para o fazer de sala de aula. Rompendo com as estruturas que limitam as práticas culturais às normatizações destaca-se o debate sobre as fronteiras da comunicação, entre o oralismo e a língua de sinais no artigo "Desfrontieres de la communication: entre l'oralisme et la langue des signes". Apresentam-se os resultados de um estudo realizado com dois jovens surdos franceses que vivem de maneira diferente, suas relações cotidianas com os ouvintes. As entrevistas foram realizadas, em setembro de 2013, em um estabelecimento de ensino especializado para surdos na região de Poitou-Charentes, França. Os resultados indicam que os avanços das novas tecnologias de informação e comunicação, a exemplo do implante coclear, levam os surdos a uma zona fronteiriça. Os surdos que utilizam o implante coclear ou aparelhos auditivos tendem a perceber os sons porque o principal objetivo dessas tecnologias é favorecer o oralismo ao passo que, tal compreensão dos sons não dá aos surdos a condição de ouvintes. Esse descompasso é interrogado e debatido pelos autores, analisando o contexto comunicativo na inclusão desse grupo de alunos surdos nessa região da França.

Em linhas gerais, para estabelecer novas perspectivas para a atuação docente sugere-se a compreensão dos processos de ensino e aprendizagem a partir da vivência do aluno no cotidiano da escola e da sala de aula. A esse processo (CASTRO, 2015) nomeou como tornar-se aluno referenciado pelas noções de identidade e pertencimento. A pesquisa realizada pela autora - Tornar-se aluno - identidade e pertencimento: perspectivas etnográficas - é apresentada na seção Resenha com destaque para a utilização da abordagem etnográfica de pesquisa para trazer a vivência dos alunos durante a escolarização e a formação profissional. Destaca-se a possibilidade de considerar o aluno como pesquisador, fornecendo significados e releituras, contribuindo para o entendimento das interações observadas no campo e análise dos dados, de modo a rever as fronteiras quanto ao papel da pesquisa e do pesquisador na escola.

Observa-se que as fronteiras, persistentes no campo educacional, dificultam as possibilidades de integrar culturas no contexto de produção do conhecimento, envolvendo os sujeitos educacionais. As culturas persistem e, num movimento fluido, ora se deslocam para o interior das escolas, ora para a universidade como possibilidade de integrar as perspectivas orientadas para a melhoria da qualidade dos processos educacionais. Esse movimento, aos poucos, ganha destaque e se fortalece no aumento das produções acadêmicas publicizando resultados de pesquisas que possam colaborar para a formação e atuação de futuros profissionais, bem como para a ressignificação de práticas educacionais. 